\title{
Multiple-locus, variable number of tandem repeat analysis (MLVA) of the fish-pathogen Francisella noatunensis
}

\author{
Øyvind J Brevik*, Karl F Ottem, Are Nylund
}

\begin{abstract}
Background: Since Francisella noatunensis was first isolated from cultured Atlantic cod in 2004, it has emerged as a global fish pathogen causing disease in both warm and cold water species. Outbreaks of francisellosis occur in several important cultured fish species making a correct management of this disease a matter of major importance. Currently there are no vaccines or treatments available. A strain typing system for use in studies of $F$. noatunensis epizootics would be an important tool for disease management. However, the high genetic similarity within the Francisella spp. makes strain typing difficult, but such typing of the related human pathogen Francisella tullarensis has been performed successfully by targeting loci with higher genetic variation than the traditional signature sequences. These loci are known as Variable Numbers of Tandem Repeat (VNTR). The aim of this study is to identify possible useful VNTRs in the genome of $F$. noatunensis.

Results: Seven polymorphic VNTR loci were identified in the preliminary genome sequence of $F$. noatunensis ssp. noatunensis GM2212 isolate. These VNTR-loci were sequenced in F. noatunensis isolates collected from Atlantic cod (Gadus morhua) from Norway $(n=21)$, Three-line grunt (Parapristipoma trilineatum) from Japan $(n=1)$, Tilapia (Oreochromis spp.) from Indonesia $(n=3)$ and Atlantic salmon (Salmo salar) from Chile $(n=1)$. The Norwegian isolates presented in this study show both nine allelic profiles and clades, and that the majority of the farmed isolates belong in two clades only, while the allelic profiles from wild cod are unique.

Conclusions: VNTRs can be used to separate isolates belonging to both subspecies of $F$. noatunensis. Low allelic diversity in F. noatunensis isolates from outbreaks in cod culture compared to isolates wild cod, indicate that transmission of these isolates may be a result of human activity. The sequence based MLVA system presented in this study should provide a good starting point for further development of a genotyping system that can be used in studies of epizootics and disease management of francisellosis.
\end{abstract}

\section{Background}

The intensive culturing of fish in artificially high population densities facilitates disease outbreaks [1,2]. Standard protocols for traditional fish health management, controlling and preventing diseases, have focused on vaccines, operational prophylactic measures and oral treatment using therapeutic agents [3]. However, in those cases where vaccines or treatments are not available, understanding the epizootiology becomes the key to prevent outbreaks and pathogen dispersal [1]. Using molecular tools for strain typing of pathogens, combined

\footnotetext{
* Correspondence: oyvind.brevik@bio.uib.no
Department of Biology, University of Bergen, Post box 7800, N-5020 Bergen,

* Correspondence: oyvind.brevik@bio.uib.no
Department of Biology, University of Bergen, Post box 7800, N-5020 Bergen, Norway
}

(c) 2011 Brevik et al; licensee BioMed Central Ltd. This is an Open Access article distributed under the terms of the Creative Commons Attribution License (http://creativecommons.org/licenses/by/2.0), which permits unrestricted use, distribution, and reproduction in any medium, provided the original work is properly cited. pathogen and the host, is a prerequisite in creating an epizootiological understanding which can be applied in management of diseases in both wild and cultured populations.

Historically, the Atlantic cod (Gadus morhua) has been an important marine resource in Norway, occurring naturally both as migratory and stationary populations [4-6]. These populations are divided into coastal and oceanic populations, based on phenotypic and genotypic traits. The Norwegian coastal cod population is considered to consist of several stationary sub populations dispersed along the Norwegian coast [7-12]. The oceanic cod in Norwegian waters can be divided into 
two populations, the North East Arctic cod and the North Sea cod, both with seasonally dependent migratory behavior. The oceanic and some of the coastal populations will, at certain times of the year, be present in at the same locations.

During the last decade cod has been a species of increasing significance and interest for the Norwegian aquaculture industry [13]. Cod is now intensively cultured with full control of all life-stages, except for the broodfish which are predominantly of wild origin $[6,14]$. The intensive production cycle of cod consists of three separate steps, where the first step starts with the fertilization of eggs from broodstock held in large land based tanks. The majority of broodfish consists of wild caught cod from both costal and oceanic populations. After hatching the fry is held in indoor tanks. The second stage is on-growth, where the fingerlings are transferred to net pens in the sea and held until they are moved to production sites. Mixing of populations from different broodstock companies occurs at the on-growth sites, i.e. before redistribution to production sites. Mixing of populations may also occur at the production sites due to limited availability of fish from the different on-growing sites. Several generations can be present at one production site. The different operational sites are dispersed along the Norwegian coast resulting in large scale movement of cultured cod between different parts of Norway [13,14].

In 2004 a Francisella species was isolated from farmed cod in Norway showing clinical signs of a chronic granulomatous infection in kidney, spleen, liver and heart [15]. The bacterium was initially characterized both as a species, F. piscicida (GM2212) [16,17], and later in the same year as a F. philomiragia subspecies, ssp. noatunensis (NCIMB $14265^{\mathrm{T}}$ ) [18]. The F. philomiragia ssp. noatunensis was later elevated to the rank of species, $F$. noatunensis ssp. noatunensis, with $F$. piscicida as a heterotypic synonym [19-22]. Following the discovery, several annual outbreaks of francisellosis have been diagnosed with main foci in the western parts of Norway [23]. The bacterium has been detected in cultured fish from Rogaland to Nordland county $\left(59-67^{\circ} \mathrm{N}\right)$, however, positive wild cod has only been identified south of Sogn og Fjordane county $\left(61^{\circ} \mathrm{N}\right)$, indicating a southern natural reservoir of the bacteria [24]. After the discovery of F. noatunensis ssp. noatunensis, histological material collected in 1988 from a broodfish population in Hordaland county, has been stained positive with antiserum for the F. noatunensis ssp. noatunensis GM2212 isolate, suggesting the presence of the bacteria in Norwegian waters prior to the initial discovery [25].

During the last 10 years members of the genus Francisella have emerged as a global problem for aquaculture, causing mortality among a wide range of aquatic hosts.
These Francisella isolates show high genetic similarities with $F$. philomiragia and with each other at the $16 \mathrm{~S}$ rRNA-gene [15,26-32]. The close genetic relatedness has been confirmed with sequencing of several housekeeping genes showing identical sequences for Norwegian isolates [18]. A Chilean isolate from Atlantic salmon (Salmo salar) UA2660 [29] showed a high similarity to the Norwegian cod isolates (NCIMB $14265^{\mathrm{T}} / \mathrm{GM} 2212$ ) and was therefore described as a new isolate of the $F$. noatunensis ssp. noatunensis [19,22]. Fish pathogenic Francisella isolates from Asia display high genetic similarity to UA2660 and NCIMB $14265^{\mathrm{T}} / \mathrm{GM} 2212$ and constitute a separate subspecies, F. noatunensis ssp. orientalis (Ehime-1) [19,20,26]. F. asiatica (PQ1104) isolated from tilapia (Oreochromis sp.) in Costa Rica is identical with $F$. noatunensis ssp. orientalis (Ehime-1) with respect to phenotype and signature sequences (rRNA and housekeeping genes) [22].

Isolates of $F$. noatunensis ssp. noatunensis from Norway are identical when comparing $16 \mathrm{~S}$ and housekeeping gene sequences [18,33], making genotyping and studies of epizootics difficult. If an epizootiological approach is to be applied for controlling and preventing dispersal of Francisella spp. in aquaculture, a tool for the identification of isolates is a necessity. Such a tool will make it possible to differentiate between wild endemic and anthropogenic dispersed strains. This approach also requires knowledge of the production history of cod and some knowledge of natural occurring strains in wild cod in the production areas. Targeting the housekeeping genes of bacterial fish pathogens has been applied for strain identification [34], but due to identical signature sequences this has not been possible to use on F. noatunensis $[18,24,33]$. Similar problems are known from epidemiological studies of human pathogenic bacteria like the Mycobacterium tuberculosis, M. avium ssp. paratuberculosis, Bacillus anthracis, Yersinia pestis and the related F. tularensis [35-38] where evolutionary or stochastic events have led to a dominance of highly fit clones making strain identification difficult [39].

By using genetic markers with higher mutational rates, like Variable Number of Tandem Repeat (VNTR), one can construct allelic profiles in Multiple Locus VNTR Analysis (MLVA) systems, making strain differentiation of clonal bacteria populations possible [40-42]. MLVA systems have already been applied in studies of $F$. tularensis isolates [43-46]. This study is an attempt to provide a sequenced based MLVA tool for studying the epizootics of F. noatunensis ssp. noatunensis in Norwegian cod farming. Our findings suggest that the MLVA system presented in this study is suitable for strain typing of F. noatunensis isolates from Norwegian cod, and the results indicate that there are only a few clades causing francisellosis outbreaks in Norwegian cod culturing. 


\section{Methods}

\section{Isolation of Francisella noatunensis ssp. noatunensis}

All isolates of Francisella noatunensis ssp. noatunensis ( $\mathrm{n}=22$ ) included in this study were obtained from Atlantic cod (Gadus morhua) suffering from francisellosis, with the exception of the type strain NCIMB $14265^{\mathrm{T}}$ [18] and the Chilean Atlantic salmon (Salmo salar) isolate UA2660 which were obtained from The National Collection of Industrial, food and Marine Bacteria (NCIMB) and Intervet Norbio AS, respectively (Table 1 ). The majority of isolates were collected from cultured populations of cod geographically dispersed along $1400 \mathrm{~km}$ of Norwegian coast line during the period from 2004 to 2009. Four isolates were obtained from wild-cod, from the counties of Aust-Agder, Vest-Agder, Rogaland and from the borders of Rogaland and Hordaland (Table 1). An overview of geographical origin of isolates is presented in Figure 1. Isolates of closely related Francisella spp., F. notunensis ssp. orientalis $(\mathrm{n}=4)$ and F. philomiragia $(\mathrm{n}=7)$, were also included in this study. Isolate FoJ-001/02 (Ehime-1) was

Table 1 Sample information of the 33 strains of Francisella spp. included in the current study

\begin{tabular}{|c|c|c|c|}
\hline Strain name & Year & Host & Location \\
\hline \multicolumn{4}{|c|}{ F. noatunensis subsp. noatunensis } \\
\hline FnnR-001/04 (GM2212) & 2004 & Atlantic cod (Gadus morhua), farmed & Rogaland county \\
\hline NCIMB 14265T & 2005 & Atlantic cod (G. morhua), farmed & Hordaland county \\
\hline FnnR-017/05 & 2005 & Atlantic cod (G. morhua), farmed & Rogaland county \\
\hline FnnC-UA2660 & 2006 & Farmed Atlantic salmon (Salmo salar) & Region X Chile \\
\hline FnnR-002/06 & 2006 & Atlantic cod (G. morhua), farmed & Rogaland county \\
\hline FnnR-003/06W & 2006 & Atlantic cod (G. morhua), wild caught & Rogaland county \\
\hline FnnR-004/06 & 2006 & Atlantic cod (G. morhua), farmed & Rogaland county \\
\hline FnnMR-005/06 & 2006 & Atlantic cod (G. morhua), farmed & Møre og Romsdalen county \\
\hline FnnN-006/06 & 2006 & Atlantic cod (G. morhua), farmed & Nordland county \\
\hline $\mathrm{FnnH}-007 / 06^{\mathrm{F}}$ & 2006 & Atlantic cod (G. morhua), farmed & Hordaland county \\
\hline FnnH-008/06W & 2006 & Atlantic cod (G. morhua), wild caught & Rogaland/Hordaland county \\
\hline FnnH-014/06 F & 2006 & Atlantic cod (G. morhua), farmed & Hordaland county \\
\hline FnnAA-009/07W & 2007 & Atlantic cod (G. morhua), wild caught & Aust Agder \\
\hline FnnVA-010/07W & 2007 & Atlantic cod (G. morhua), wild caught & Vest-Agder \\
\hline FnnMR-011/07 & 2007 & Atlantic cod (G. morhua), farmed & Møre og Romsdalen county \\
\hline FnnSF-012/07 & 2007 & Atlantic cod (G. morhua), farmed & Sogn og Fjordane county \\
\hline FnnMR-013/07 & 2007 & Atlantic cod (G. morhua), farmed & Møre og Romsdalen county \\
\hline FnnMR-015/08 F & 2008 & Atlantic cod (G. morhua), farmed & Møre og Romsdalen county \\
\hline $\mathrm{FnnH}-016 / 08^{\mathrm{F}}$ & 2008 & Atlantic cod (G. morhua), farmed & Hordaland county \\
\hline FnnSF-018/09 & 2009 & Atlantic cod (G. morhua), farmed & Sogn og Fjordane county \\
\hline FnnSF-019/09 & 2009 & Atlantic $\operatorname{cod}(G$. morhua), farmed & Sogn og Fjordane county \\
\hline FnnH-020/09 & 2009 & Atlantic cod (G. morhua), farmed & Hordaland county \\
\hline \multicolumn{4}{|c|}{ F. noatunensis subsp. orientalis } \\
\hline FnoJ-001/02 (Ehime-1) ${ }^{B}$ & 2002 & Farmed Three-line grunt (Parapristipoma trilineatum) & Ehime prefecture, Japan \\
\hline Fnol-002/04c & 2004 & Farmed tilapia (Oreochromis spp.) & Lake Toba, Indonesia \\
\hline Fnol-003/05 & 2005 & Farmed tilapia (Oreochromis spp.) & Lake Toba, Indonesia \\
\hline Fnol-004/07C (Ind04) & 2007 & Farmed tilapia (Oreochromis spp.) & Lake Wadaslingtan, Indonesia \\
\hline \multicolumn{4}{|l|}{ F. philomiragia } \\
\hline FpDSM7535T & 1959 & Muskrat from Bear River refuge & Utah, USA \\
\hline FpCCUG19701 & 1960 & Water, from a river in Bear River refuge & Utah, USA \\
\hline FpCCUG13404 & 1979 & Human, bone marrow & Zurich, Switzerland \\
\hline FpCCUG12603 & 1982 & Human, abscess & Gøteborg, Sweden \\
\hline Fp1951 & 2003 & Human, blood & Denmark \\
\hline Fp080107- $-\left.\right|^{E}$ & 2007 & Environmental sample direct isolation & Marthas Vineyard, USA \\
\hline Fp080107- $-\|^{E}$ & 2007 & Environmental sample after passage through a mice & Marthas Vineyard, USA \\
\hline
\end{tabular}

The table show source and geographical location of isolation for the Francisella isolates $(n=33)$ included in the current study. Norway is country of origin unless otherwise is stated.

Isolates were kindly provided by Intervet Norbio $\mathrm{AS}^{\mathrm{A}}$, Dr. Kamaishi ${ }^{\mathrm{B}}$, Intervet Singapore ${ }^{\mathrm{C}}$, Dr. Friis-Møller ${ }^{\mathrm{D}}$ and $\mathrm{Dr}^{\text {. Berrada }}$

Isolated from broodfish ${ }^{\mathrm{F}}$, Isolated in Chile ${ }^{\mathrm{A}}, \mathrm{W}=$ wild caught, $\mathrm{T}=$ type strain 


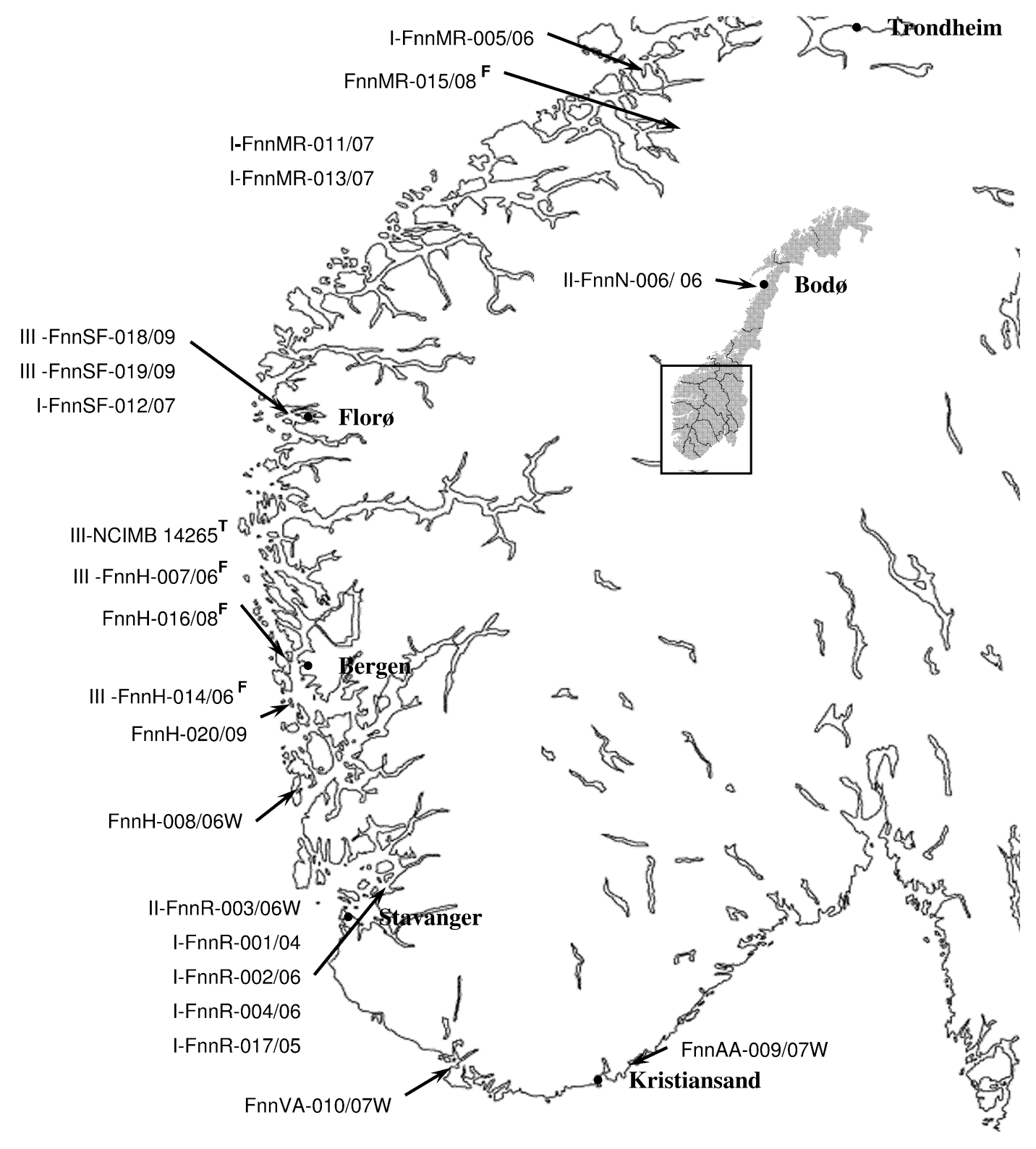

Figure 1 The geographical location of sampling sites of the Norwegian $F$. noatunensis ssp. noatunensis isolates $(n=21)$. Accurate location of FnnMR-011/07 and FnnMR-013/07 is unknown. Isolates from production sites of cultured cod is predominantly of clade I and III. I = clade I, II = clade II, II = clade III, W = wild caught, broodfish ${ }^{\mathrm{F}}$, type strain ${ }^{\top}$.

kindly provided by Dr. Kamaishi, and isolates FoI-002/04, FoI-003/05 and FoI-004/07 from Indonesia were kindly provided by Intervet Singapore. Most $F$. philomiragia isolates were obtained from the culture collections Deutsche Sammlung von Mikroorganismen und Zellkulturen (DSMZ) and Culture Collection, University of Göteborg (CCUG), while strains 080107 and strain 1951[47,48] were kindly provided by Dr. Berrada and Dr. Friis-Møller, respectively. A complete overview of isolates and year of isolation, host and location is presented in Table 1.

\section{Culture of $F$. noatunensis ssp. noatunensis}

Isolations of $F$. noatunensis ssp. noatunensis were performed in the field or in our laboratory by streaking tissue 
(head kidney and/or spleen) from infected cod on agar plates. Initial isolations were performed using blood agar plates with $0.1 \%$ cysteine and $1 \%$ glucose as described by Nylund et al. (2006) with subsequent growth in B1817 broth for cryopreservation [33]. However, most isolations were performed using Cysteine Heart Agar (Difco) supplemented with $5 \%$ bovine blood (CHAB) as described in Olsen et al. (2006) with slight modifications. These included the addition of $50 \mu \mathrm{g} \mathrm{ml}^{-1}$ of ampicillin, 50-100 $\mu \mathrm{g} \mathrm{ml}^{-1}$ of fungizone ${ }^{\circledR}$ and additional cysteine to a final concentration of $0.2 \%$. The ampicillin, fungizone ${ }^{\circledR}$, bovine blood and cysteine were added to the $\mathrm{CHAB}$ at $60^{\circ} \mathrm{C}$. All isolates were incubated at $20^{\circ} \mathrm{C}$ for 2-4 days (F. philomiragia) or two weeks (F. noatunensis). A Sanyo MIR-554 incubator was used for solid cultures whereas liquid culturing was performed in an Infors Unitron incubator at $250 \mathrm{rpm}$. Colonies from CHAB agar were dissolved in Eugon Broth (Difco) for cryopreservation and stored in liquid nitrogen.

\section{Genomic analysis}

A preliminary genomic sequence from Francisella noatunensis ssp. noatunensis isolate GM2212 (= F. piscicida, DSM $18777^{\mathrm{T}}$, CNCM-3511 ${ }^{\mathrm{T}}$, LMG24256 ${ }^{\mathrm{T}}$ ) was analyzed for the presence of tandem repeat regions using the software Tandem Repeats Finder [49]. This program locates and displays tandem repeats in DNA sequences. Loci with tandem repeats consisting of less than 15 nucleotides and more than four repeats were selected (Table 2). The preliminary genomic sequence of $F$. noatunensis ssp. noatunensis isolate GM2212 was generated using the 454 pyro-sequencing technology $[50,51]$ in cooperation with Intervet AS/ASA.

\section{DNA extraction}

Total DNA from all collected strains and tissues was extracted using the DNeasy ${ }^{\circledR}$ blood \& tissue kit (Qiagen) as described by the manufacturer.

\section{PCR and amplification of VNTR loci}

Based on results from the tandem repeats analysis, oligonucleotide primers flanking 11 potential VNTR loci was designed using the Vector NTI Suite 9.0 program package (InforMax Inc.). In addition, two pairs of flanking primers, VNTR1-2F/R and VNTR2-2F/R were designed for the purpose of nested PCR, as not all isolates were amplified using the initial primers. The oligonucleotide primers had $\mathrm{Tm}$ ranging from 40.9 to $55.4^{\circ} \mathrm{C}$, and the annealingtemperature for each primer combination was therefore optimized using gradient PCR with the isolate GM2212 DNA as template (Table 3 ). The amplification was performed in a $50 \mu \mathrm{l}$ reaction mixture containing $10 \mathrm{X}$ buffer (Promega) including $1.5 \mathrm{mmol}^{-1} \mathrm{MgCl}_{2}, 2.5 \mathrm{mM} \mathrm{dNTP}$ (Promega), $10 \mu^{-1} \mathrm{~mol}^{-1}$ of each primer (Invitrogen), $2 \mu \mathrm{l}$ DNA and $0.6 \mathrm{U}$ Thermal Ace ${ }^{\mathrm{TM}} \mathrm{DNA}$ polymerase (Invitrogen). Amplification was carried out in a Mastercycler gradient (Eppendorf) with denaturation at $95^{\circ} \mathrm{C}$ for $5 \mathrm{~min} ; 35$ cycles with denaturation at $95^{\circ} \mathrm{C}$ for $30 \mathrm{~s}$, annealing at $\mathrm{X}^{\circ} \mathrm{C}$ (optimized annealing temperature Table 3 ) for $45 \mathrm{~s}$ and extension at $72^{\circ} \mathrm{C}$ for $1 \mathrm{~min}$, followed by prolonged extension at $72^{\circ} \mathrm{C}$ for $10 \mathrm{~min}$ and a short storage at $4^{\circ} \mathrm{C}$. All PCR-products were visualized using gel-electrophoresis. In cases where the initial PCR did not amplify a target sequence, several techniques were applied including nested- (VNTR 1 and 2), touchdown- and gradient-PCR. In the touchdown PCR, the amplification cycles were as follows; denaturation at $95^{\circ} \mathrm{C}$ for $5 \mathrm{~min}$; followed by 6 times of 3 cycles of; denaturation at $94^{\circ} \mathrm{C}$ for $45 \mathrm{~s}$, annealing for $45 \mathrm{~s}$ at $66-51^{\circ} \mathrm{C}$ with a reduction of $3^{\circ} \mathrm{C}$ at each cycle, and extension at $72^{\circ} \mathrm{C}$ for $1 \mathrm{~min}$. The rounds of touchdown were immediately followed by 25 cycles with denaturation at $94^{\circ} \mathrm{C}$ for $45 \mathrm{~s}$, annealing at $48^{\circ} \mathrm{C}$ for $45 \mathrm{~s}$, extension at $72^{\circ} \mathrm{C}$ for $1 \mathrm{~min}$; and a final extension at $72^{\circ} \mathrm{C}$ for $10 \mathrm{~min}$ before a short storage at $4^{\circ} \mathrm{C}$. The gradient PCR amplification was as follows: denaturation at $95^{\circ} \mathrm{C}$ for $5 \mathrm{~min}$; denaturation at $94^{\circ} \mathrm{C}$ for $45 \mathrm{~s}, 2$ and $4^{\circ} \mathrm{C}$ below and over optimized annealing temperature (Table 3) for $45 \mathrm{~s}$, extension at $72^{\circ} \mathrm{C}$ for $1 \mathrm{~min}$; and a final extension at $72^{\circ} \mathrm{C}$ for $10 \mathrm{~min}$ before a short storage at $4^{\circ} \mathrm{C}$.

\section{Sequencing of VNTR loci}

In order to identify repeat copy number variation among the isolates in question the resulting PCR-products were

Table 2 Attributes of the Variable Number of Tandem Repeat loci among F. noatunensis isolates

\begin{tabular}{|c|c|c|c|c|c|}
\hline Marker locus & GenBank Accesion no & Repeat sequence & Repeats in GM2212 & Amplicon/repeat span & No. alleles \\
\hline$\overline{\text { Fnn-VNTR1 }}{ }^{\text {NA }}$ & GU385767 & TTAAGGTA & 7 & $195-219 / 5-8$ & 3 \\
\hline Fnn-VNTR2 & GU385768 & AGTTATT & 8 & 217-392/8-33 & 7 \\
\hline Fnn-VNTR3 $^{N A}$ & GU385769 & TAGAT & 10 & $197-212 / 7-10$ & 4 \\
\hline Fnn-VNTR4 & GU385770 & TTGTGG & 10 & $311-437 / 10-31$ & 11 \\
\hline Fnn-VNTR5 ${ }^{N A}$ & GU385771 & AAAAGGTAT & 5 & $285-312 / 2-5$ & 2 \\
\hline Fnn-VNTR6 & GU385772 & CTG & 10 & 295-307/8-12 & 3 \\
\hline Fnn-VNTR7 & GU385773 & ПाTन & 5 & $404-435 / 1.8-5$ & 4 \\
\hline
\end{tabular}

GenBank Accession numbers refer to sequences of the $F$. noatunensis ssp. noatunensis GM2212 isolate. Repeat sequence, number of repeats and amplicon size is that of the GM2212 isolate.

Not amplified within F. philomiragia isolates ${ }^{\mathrm{NA}}$. 
Table 3 Primers used to amplify the VNTR regions included in the study

\begin{tabular}{|c|c|c|c|c|c|}
\hline Primer-name & Sequence & $\mathrm{Tm}^{\circ} \mathrm{C}$ & Target & Optimized $\mathrm{Tm}^{\circ}$ & Amplicon size \\
\hline Fnn-VNTR1F & ATCTTGGAAATTAACTACTITC & 46.1 & VNTR no 1 & 55 & 211 \\
\hline Fnn-VNTR1R & ACCTITTCTACACCAATAG & 47.2 & & & \\
\hline Fnn-VNTR2F & GTAAACGTAGTITITGGAAGTCCAT & 53.7 & VNTR no 2 & 54 & 217 \\
\hline Fnn-VNTR2R & GGATGGCAATCTTGTGTAAA & 50.7 & & & \\
\hline Fnn-VNTR3F & CAAACCTTCATCTCCACTAC & 50.4 & VNTR no 3 & 50 & 212 \\
\hline Fnn-VNTR3R & TGCTCTITTCCCTCTATATA & 47.2 & & & \\
\hline Fnn-VNTR4F & AGTTTCATTTATCAGGTGAC & 47.5 & VNTR no4 & 54 & 311 \\
\hline Fnn-VNTR4R & AGACTAATAGCCTTCCAAAA & 48.5 & & & \\
\hline Fnn-VNTR5F & CTGGACATTAGTATCAGGAT & 48.3 & VNTR no 5 & 55 & 312 \\
\hline Fnn-VNTR5R & GCAGTGGTAACAATTTTAAG & 47.2 & & & \\
\hline Fnn-VNTR6F & GCTGTTGGAGATAGTAAATAATTGC & 52.3 & VNTR no 6 & 55 & 301 \\
\hline Fnn-VNTR6R & TTAGCTTCTTTAAGACCAAG & 47.2 & & & \\
\hline Fnn-VNTR7F & CTTCTTCTCAACCATACCAG & 50.1 & VNTR no 7 & 54 & 439 \\
\hline Fnn-VNTR7R & ACAAGCATATAGACTTATATTGA & 46.9 & & & \\
\hline Fnn-VNTR1-2F & AAATGTAGAGTTTCCATCCAAC & 47.1 & VNTR no 1 & 55 & 613 \\
\hline Fnn-VNTR1-2R & AGTCGTATTTCTGCTTCAATC & 45.6 & & & \\
\hline Fnn-VNTR2-2F & CATGGGCTACTIITGGAATATATAC & 47.7 & VNTR no 2 & 55 & 559 \\
\hline Fnn-VNTR2-2R & TCGGTTTGACTGATGTCATG & 44.6 & & & \\
\hline
\end{tabular}

Flanking primers were designed based on preliminary data of the whole genome sequence of $F$. noatunensis ssp. noatunensis isolate GM2212. The attributes of the primers in the study; primer sequence, optimized annealing temperature ( $\mathrm{Tm}^{\circ}$ ) and amplicon size of the GM2212 isolate.

sequenced for each VNTR locus. PCR products were purified using the E.Z.N.A Cycle-Pure Kit (OMEGA) as described by the manufacturer. Sequencing was then performed in both directions using the PCR-primers (Table 3) and the ABI PRISM BigDye terminator chemistry (version 3.1) according to Applied Biosystems (ABI). All sequences were assembled using the Vector NTI Suite 9.0 program (InforMax Inc.). Possible genetic location of sequenced VNTR-loci was identified by GeneBank blastn searches performed using the complete amplicon sequence from each primer pair from either F. philomiragia or F. noatunensis ssp. noatunensis GM2212 isolate.

\section{Phylogenetic analysis}

At each VNTR locus in a single taxon, the VNTR was coded as a discrete character (i.e. 1-9, A-H) based upon the specific number of repeats at the region in question. These allele profiles were used to construct a data matrix within the Mesquite System for Phylogenetic Analysis (Maddison, W. P. and D.R. Maddison. 2009. Mesquite: a modular system for evolutionary analysis. Version 2.71 http://mesquiteproject.org). The datamatrix was exported as a nexus file into PAUP 4.0 (Swofford, D. L. 2003. PAUP*. Phylogenetic Analysis Using Parsimony ("and Other Methods). Version 4. Sinauer Associates, Sunderland, Massachusetts)) for phylogenetic analysis using the neighbor-joining (NJ) distance method [52]. The phylogenetic NJ analysis was not bootstrapped as there were too few characters and taxa for correct estimation of sampling error.

\section{Test of VNTR stability}

Since VNTR regions are considered to be one of the fastest evolving sequences of a genome, it was important to test the stability of the selected VNTR regions both in vitro and in vivo [53]. Mutations in VNTR regions have been shown during in vitro growth of both Yersinia pestis and Escherichia coli $[54,55]$. Therefore the effect of multiple passages of the $F$. noatunensis ssp. noatunensis GM2212 isolate on VNTR stability was tested as follows: a frozen first passage culture of the GM2212 isolate was streaked for isolation on $\mathrm{CHAB}$, one single colony was transferred in each passage for 10 passages. DNA isolation, PCR and sequencing were performed on a colony from passage 10 as described above. PCR and sequencing were performed for all VNTR loci for verification of copy numbers (GM2212-P10 Table 4). The in vivo stability of F. noatunensis ssp. noatunensis GM2212 isolate was tested at different temperatures with material from challenge experiments described below. Copy numbers at each VNTR locus was confirmed through direct sequencing using DNA extracted from kidney tissues of challenged fish as templates (Table 4). Kidney tissue from one cod in each group challenged with GM2212, and held at 10 (F10), 14 (F14) and $18^{\circ} \mathrm{C}$ (F18), was sampled for extraction of bacterial DNA for direct sequencing. Tank conditions for all groups were as for the challenge experiment of the F10 group described in Nylund et al. (2006) [15]. The F14 and F18 group were bath challenged in $20 \mathrm{l}$ of sea water containing a final concentration of $2.25 \times 10^{6}$ bacteria $/ \mathrm{ml}$. The bacterial suspension was prepared by inoculating 
Table 4 Allelic profiles from the stability testing

\begin{tabular}{llllllll}
\hline Isolate & VNTR1 & VNTR2 & VNTR3 & VNTR4 & VNTR5 & VNTR6 & VNTR7 \\
\hline GM2212 & $\mathbf{2 1 1 n t - 7 r}$ & $\mathbf{2 1 7 n t}-\mathbf{8 r}$ & $\mathbf{2 1 2 n t - 1 0 r}$ & $\mathbf{3 1 1 n t - 1 0 r}$ & $\mathbf{3 1 2 n t - 5 r}$ & $\mathbf{3 0 1 n t - 1 0 e r}$ & $\mathbf{4 3 5 n t - 5 r}$ \\
GM2212-P10 & $219 n t-8 r$ & $217 n t-8 r$ & $212 n t-10 r$ & $311 n t-10 r$ & $312 n t-5 r$ & $301 n t-10 e r$ & $435 n t-5 r$ \\
FC10 & $211 n t-7 r$ & $217 n t-8 r$ & $212 n t-10 r$ & $311 n t-10 r$ & $312 n t-5 r$ & $301 n t-10 e r$ & $435 n t-5 r$ \\
FC14 & $211 n t-7 r$ & $217 n t-8 r$ & $212 n t-10 r$ & $311 n t-10 r$ & $312 n t-5 r$ & $301 n t-10 e r$ & $435 n t-5 r$ \\
Fc18 & $211 n t-7 r$ & $217 n t-8 r$ & $212 n t-10 r$ & $311 n t-10 r$ & $312 n t-5 r$ & $395 n t-9 e r$ & $435 n t-5 r$ \\
\hline
\end{tabular}

In vivo stability was shown on passage 10 (P10) of the GM2212 isolate and in vitro stability on infected cod held at 10 (Fc10), 14 (Fc14) and $18^{\circ} \mathrm{C}$ ( $\left.\mathrm{Fc} 18\right)$. Results are displayed with number of nucleotides in repeat marker and numbers of repeats. Two shifts were observed in GM2212, VNTR-1 after 10 passages on CHAB agar at $20^{\circ} \mathrm{C}$ and in VNTR- 6 after passage in cod held at $18^{\circ} \mathrm{C}$. The original sequence is shown in bold, whereas the mutations are in italics.

Heterogeneous repeats with Single nucleotide polymorphism (snp), noted as nucleotide number in repeat sequence (nt) and at repeat of occurrence ( $r$ ); e $=2$ snp C-T nt1 r4 r6.

several CHAB plates with the GM2212 isolate, harvesting + mixing of bacterial cultures in PBS and subsequently adding this to sea water. Tissues were sampled from the fish 90 days post challenge. The challenge experiments were approved by the Norwegian Animal Research Authorities (NARA).

\section{VNTR linkage disequilibrium}

Linkage disequilibrium was calculated as standardized index of association $\left(I_{\mathrm{A}}^{\mathrm{S}}\right)$, for all Norwegian $F$. noatunensis ssp. noatunensis isolates $(\mathrm{n}=21)$ within the seven VNTR loci using the LIAN Linkage Analysis 3.5 online tool [56].

\section{Accession numbers}

Sequences of all seven VNTR loci from the GM2212 isolate of $F$. noatunensis ssp. noatunensis were assigned GeneBank accession numbers as follows: VNTR-1: GU385767, VNTR-2: GU385768, VNTR-3: GU385769, VNTR-4: GU385770, VNTR-5: GU385771, VNTR-6: GU385772, VNTR-7: GU385773

\section{Results}

\section{Variable Number of Tandem Repeats (VNTR) features}

Sequencing of Francisella noatunensis and F. philomiragia isolates (Table 1) showed variation in seven of the 11 tested VNTR loci (Table 5). The remaining four VNTR loci were discarded as they did not get amplified from all $F$. noatunesis isolates or showed no allelic variation among the isolates included in this study. The seven VNTR loci used in this study had an allelic diversity ranging from two (VNTR-5) to 17 (VNTR-4) alleles in all isolates included $(\mathrm{n}=33)$. The largest observed variation in allele sizes was found in VNTR-4 and spanned from one to 32 repeats in F. philomiragia isolates Fp080107-II and Fp1951, respectively. Primers for the seven informative VNTR loci (Table 3) provided PCR-products for all F. noatunensis ssp. noatunensis and orientalis isolates with the exception of VNTR-1 in isolate UA2660 and VNTR-3 in Ehime-1. VNTR-2 and 4 showed most variation among the $F$. noatunensis ssp. noatunensis isolates $(\mathrm{n}=22)$, with seven different alleles in each, while only minor variation, two different alleles, was found in VNTR-5. The F. noatunensis ssp. orientalis isolates $(\mathrm{n}=4)$ had identical alleles at VNTR-5 and -6 , while VNTR-4 was shown to be the most polymorphic with four different alleles. The repeats and attributes of each VNTR locus in F. noatunensis can be viewed in table 2 . VNTR-4, -6 and -7 were successfully amplified from all isolates of $F$. philomiragia included in this study. It was not possible to amplify VNTR-2 from the $F$. philomiragia isolate, Fp080107-I [48], and, with the exception of the amplification of VNTR-3 from DSM $7535^{\mathrm{T}}$, it was not possible to amplify VNTR-1, -3 and -5 from these isolates (Table 5). Among the F. philomiragia isolates most allele variation was seen in VNTR-4, whereas no variations were detected in sequences from VNTR-2 and -6. It is not known if the lack of a PCR product for a given VNTR locus is a result of primer mismatch or absence of the VNTR locus in question. Due to the preliminary status of the genome from which the VNTR loci were identified, the genomic locations of the loci remain unknown. Possible locations of the VNTR loci within the genome of $F$. philomiragia were identified by GeneBank blastn searches. The following matches were identified (Table 6); VNTR-2 locus (186 bp query) matched the intergenic segment located between the genes encoding the Bor lipoprotein and Nicotinamide Adenine Dinucleotide Phosphate -quinone reductase (1900473-1900533bp), VNTR-4 sequence (394 bp query) matched the intragenic segment in the DNA-directed DNA polymerase gene (695610- 695415), VNTR-6 sequence (327 bp query) matched the segment intragenically located in $50 \mathrm{~S}$ ribosomal protein L10 gene (1129799-1130125) ,VNTR-7 sequence ( 458 bp query) matched the intragenically located segment between and within the genes encoding the FTN_1059 hypothetical protein and trigger factor protein (1661303-1660846). No significant matches were identified for VNTR-3. VNTR-5 and -1 were not amplified from DSM 7535 , but a blastn search was performed using these VNTR sequences obtained from $F$. noatunensis ssp. noatunensis GM2212 isolate. VNTR-5 displayed intragenic match for a gene encoding the FTN_0396 hypothetical protein (495433496083) with $99 \%$ sequence-identity and $E$ value of 
Table 5 Allelic profiles of the 33 Francisella isolates used in the study.

\begin{tabular}{|c|c|c|c|c|c|c|c|c|}
\hline Allelic profile & Strain name & Fnn-VNTR1 & Fnn-VNTR2 & Fnn-VNTR3 & Fnn-VNTR4 & Fnn-VNTR5 & Fnn-VNTR6 & Fnn-VNTR7 \\
\hline & \multicolumn{8}{|c|}{ F. noatunensis ssp. Noatunensis } \\
\hline & FnnUA2660 ${ }^{A}$ & NA & $392 n t-33 r$ & $212 n t-10 r$ & $335 \mathrm{nt}-14 \mathrm{br}$ & $285 n t-2 r$ & $307 \mathrm{nt}-12 \mathrm{hr}$ & $405 n t-2 i r$ \\
\hline । & FnnR-001 -04 (GM2212) ${ }^{\top}$ & $211 n t-7 r$ & $217 n t-8 r$ & $212 n t-10 r$ & $311 n t-10 r$ & $312 n t-5 r$ & $301 n t-10 e r$ & $435 n t-5 r$ \\
\hline । & FnnR-002 - 06 & $211 n t-7 r$ & $217 n t-8 r$ & $212 n t-10 r$ & $311 n t-10 r$ & $312 n t-5 r$ & $301 n t-10 e r$ & $435 n t-5 r$ \\
\hline । & FnnR-004 - 06 & $211 n t-7 r$ & $217 n t-8 r$ & $212 n t-10 r$ & $311 n t-10 r$ & $312 n t-5 r$ & $301 n t-10 e r$ & $435 n t-5 r$ \\
\hline । & FnnR-017 - 05 & $211 \mathrm{nt}-7 \mathrm{r}$ & $217 n t-8 r$ & $212 n t-10 r$ & $311 n t-10 r$ & $312 n t-5 r$ & $301 n t-10 e r$ & $435 n t-5 r$ \\
\hline । & FnnMR-005 - 06 & $211 n t-7 r$ & $217 n t-8 r$ & $212 n t-10 r$ & $311 \mathrm{nt}-10 \mathrm{r}$ & $312 n t-5 r$ & $301 \mathrm{nt}-10 \mathrm{er}$ & $435 n t-5 r$ \\
\hline । & FnnMR-011 - 07 & $211 \mathrm{nt}-7 \mathrm{r}$ & $217 n t-8 r$ & $212 n t-10 r$ & $311 n t-10 r$ & $312 n t-5 r$ & $301 \mathrm{nt}-10 \mathrm{er}$ & $435 n t-5 r$ \\
\hline । & FnnSF-012 - 07 & $211 n t-7 r$ & $217 n t-8 r$ & $212 n t-10 r$ & $311 n t-10 r$ & $312 n t-5 r$ & $301 \mathrm{nt}-10 \mathrm{er}$ & $435 n t-5 r$ \\
\hline । & FnnMR-013 - 07 & $211 \mathrm{nt}-7 \mathrm{r}$ & $217 n t-8 r$ & $212 n t-10 r$ & $311 n t-10 r$ & $312 n t-5 r$ & $301 \mathrm{nt}-10 \mathrm{er}$ & $435 n t-5 r$ \\
\hline$\|$ & FnnR-003 - 06W & $211 n t-7 r$ & $217 n t-8 r$ & $207 n t-9 r$ & $311 n t-10 r$ & $312 n t-5 r$ & $301 \mathrm{nt}-10 \mathrm{er}$ & $435 n t-5 r$ \\
\hline$\|$ & FnnN-006 - 06 & $211 n t-7 r$ & $217 n t-8 r$ & $207 n t-9 r$ & $311 n t-10 r$ & $312 n t-5 r$ & $301 n t-10 e r$ & $435 n t-5 r$ \\
\hline III & $\mathrm{FnnH}-007-06^{\mathrm{F}}$ & $219 n t-8 r$ & $259 n t-14 r$ & $202 n t-8 r$ & $341 n t-15 r$ & $312 n t-5 r$ & $301 \mathrm{nt}-10 \mathrm{er}$ & $430 n t-4 r$ \\
\hline III & NCIMB $14265^{\top}$ & $219 n t-8 r$ & $259 n t-14 r$ & $202 n t-8 r$ & $341 n t-15 r$ & $312 n t-5 r$ & $301 \mathrm{nt}-10 \mathrm{er}$ & $430 n t-4 r$ \\
\hline III & $\mathrm{FnnH}-014-06^{\mathrm{F}}$ & $219 n t-8 r$ & $259 n t-14 r$ & $202 n t-8 r$ & $341 n t-15 r$ & $312 n t-5 r$ & $301 \mathrm{nt}-10 \mathrm{er}$ & $430 n t-4 r$ \\
\hline III & FnnSF-018-09 & $219 n t-8 r$ & $259 n t-14 r$ & $202 n t-8 r$ & $341 n t-15 r$ & $312 n t-5 r$ & $301 \mathrm{nt}-10 \mathrm{er}$ & $430 n t-4 r$ \\
\hline \multirow[t]{20}{*}{ III } & FnnSF-019- 09 & $219 n t-8 r$ & $259 n t-14 r$ & $202 n t-8 r$ & $341 n t-15 r$ & $312 n t-5 r$ & $301 \mathrm{nt}-10 \mathrm{er}$ & $430 n t-4 r$ \\
\hline & $\mathrm{FnnH}-008-06 \mathrm{~W}$ & $195 n t-5 r$ & $217 n t-8 r$ & $202 n t-8 r$ & $311 n t-10 r$ & $312 n t-5 r$ & $301 \mathrm{nt}-10 \mathrm{er}$ & $435 n t-5 r$ \\
\hline & FnnMR-015 $-08^{F}$ & $195 n t-5 r$ & $259 n t-14 r$ & $197 \mathrm{nt}-7 \mathrm{r}$ & $437 n t-31 r$ & $312 n t-5 r$ & $301 \mathrm{nt}-10 \mathrm{er}$ & $435 n t-5 r$ \\
\hline & $\mathrm{FnnH}-016-08^{\mathrm{F}}$ & $219 n t-8 r$ & $287 n t-18 r$ & $197 n t-7 r$ & $359 n t-18 r$ & $312 n t-5 r$ & $295 n t-8 e r$ & $435 n t-5 r$ \\
\hline & FnnAA-009 - 07W & $211 \mathrm{nt}-7 \mathrm{r}$ & $294 n t-19 r$ & $197 n t-7 r$ & $347 n t-16 r$ & $312 n t-5 r$ & $301 n t-10 e r$ & $435 n t-5 r$ \\
\hline & FnnVA-010 - 07W & $211 \mathrm{nt}-7 \mathrm{r}$ & $308 n t-21 r$ & $197 n t-7 r$ & $329 n t-13 r$ & $312 n t-5 r$ & $301 n t-10 e r$ & $435 n t-5 r$ \\
\hline & FnnH-020 - 09 & $195 n t-5 r$ & $280 n t-17 r$ & $207 n t-9 r$ & $437 n t-31 r$ & $312 n t-5 r$ & $301 n t-10 e r$ & $435 n t-5 r$ \\
\hline & \multicolumn{8}{|l|}{ F. noatunensis ssp. orientalis } \\
\hline & FnoJ-001 - 02 (Ehime-1) & $195 n t-5 r$ & $217 n t-8 r$ & NA & $317 n t-11 d r$ & $285 n t-2 r$ & $301 \mathrm{nt}-10 \mathrm{fr}$ & $405 n t-2 i r$ \\
\hline & Fnol-002 - 041368 & $211 \mathrm{nt}-7 \mathrm{r}$ & $392 n t-33 r$ & $212 n t-10 r$ & $365 n t-19 d r$ & $285 n t-2 r$ & $301 \mathrm{nt}-10 \mathrm{fr}$ & $404 n t-1.8 r$ \\
\hline & Fnol-003 - 051436 & $211 \mathrm{nt}-7 \mathrm{r}$ & $217 n t-8 r$ & $212 n t-10 r$ & $329 n t-13 d r$ & $285 n t-2 r$ & $301 \mathrm{nt}-10 \mathrm{fr}$ & $404 n t-1.8 r$ \\
\hline & Fnol-004 - 072070 & $211 n t-7 r$ & $217 n t-8 r$ & $212 n t-10 r$ & $371 n t-20 d r$ & $285 n t-2 r$ & $301 \mathrm{nt}-10 \mathrm{fr}$ & $404 n t-1.8 r$ \\
\hline & \multicolumn{8}{|l|}{ F. philomiragia } \\
\hline & FpDSM7535T & NA & $175 \mathrm{nt}-2.8 \mathrm{br}$ & $182 \mathrm{nt}-4 \mathrm{c}$ & $401 n t-25 d r$ & NA & $301 \mathrm{nt}-10 \mathrm{gr}$ & $404 n t-1.8 r$ \\
\hline & FpCCUG19701 & NA & $175 \mathrm{nt}-2.8 \mathrm{br}$ & NA & $395 n t-24 d r$ & NA & $301 \mathrm{nt}-10 \mathrm{gr}$ & $405 n t-2 r$ \\
\hline & FpCCUG13404 & NA & $175 \mathrm{nt}-2.8 \mathrm{br}$ & NA & $311 \mathrm{nt}-10 \mathrm{dr}$ & NA & $301 \mathrm{nt}-10 \mathrm{gr}$ & $404 n t-1.8 r$ \\
\hline & FpCCUG12603 & NA & $175 \mathrm{nt}-2.8 \mathrm{br}$ & NA & $407 n t-26 d r$ & NA & $301 \mathrm{nt}-10 \mathrm{gr}$ & $425 n t-3 r$ \\
\hline & Fp1951 & NA & $175 n t-2.8 a r$ & NA & $443 n t-32 r$ & NA & $301 \mathrm{nt}-10 \mathrm{gr}$ & $404 n t-1.8 r$ \\
\hline & Fp080107 -I & NA & $\mathrm{Na}$ & NA & $431 \mathrm{nt}-30 \mathrm{dr}$ & NA & $301 \mathrm{nt}-10 \mathrm{gr}$ & $405 n t-2 r$ \\
\hline & Fp080107 -II & NA & $175 n t-2.8 a r$ & NA & 257nt - 1ar & NA & $301 \mathrm{nt}-10 \mathrm{gr}$ & $404 n t-1.8 r$ \\
\hline
\end{tabular}

Identical allelic profiles are assigned Greek numerals I-III. Allelic profiles are presented as number of nucleotides in repeat marker (nt) and numbers of repeats ( $\mathrm{r}$ ). Identical profiles occur for several isolates from cod culturing, profile I (FnnR-001-04 to FnnMR-013-07), profile II (FnnR-003-06W and FnnN-006-06) and profile III (FnnH-007-06 to FnnSF-019-09).

Isolated in Chile ${ }^{\mathrm{A}}$, Isolated from broodfish ${ }^{\mathrm{F}}$, type $\operatorname{strain}^{\top}, \mathrm{W}=$ wild caught, NA = Not Amplified with primer sets

Heterogeneous repeats with Single Nucleotide Polymorphism (snp), noted as nucleotide number in repeat sequence (nt) and at repeat of occurrence $(r) ; a=s n p$ G-A nt1 r1 r3 b = snp. G-A nt1 r3, $c=$ snp G-A nt3 r4, $d=$ snp T-C nt1 from r2, e = 2 snp C-T nt1 r4 r6, f = 2 snp C-T nt1 r5 r7, g = 2 snp C-T nt1 r6 r8, h = 2 snp C-T nt1 r8 r10, i = snp T-C nt4 r1

$3 \times 10^{-79}$, while VNTR-1 showed no significant match to the F. philomiragia genome.

\section{Allele profiles}

Variation in the VNTR loci was revealed by sequencing, and these data were used to create allele profiles for all isolates. Lack of amplifiable VNTR locus was interpreted as a separate "missing" character. A complete overview of the allele profiles is presented in Table 5. Analysis of the seven VNTR loci revealed a total of 10 unique allele profiles among the $22 \mathrm{~F}$. noatunensis ssp. noatunensis isolates. Three of the profiles contained more than one 
Table 6 Location of Blastn matches from Variable Number of Tandem Repeat -sequences from F. philomiragia DSM7535

\begin{tabular}{llllll}
\hline Marker locus & BP in query & Identity & Location & Adjacent genes & E-value \\
\hline Fnn-VNTR2 & 186 & $96 \%$ & Intergenic (1900473-1900533) & Bor lipoprotein/NADPH-quinone reductase & $7 \times 10^{-28}$ \\
Fnn-VNTR4 & 394 & $97 \%$ & Intragenic (695610- 695415) & DNA-directed DNA polymerase & $1 \times 10^{-88}$ \\
Fnn-VNTR5 ${ }^{\text {A }}$ & 333 & $99 \%$ & Intragenic (495433-496083) & FTN_0396 hypothetical protein & $3 \times 10^{-79}$ \\
Fnn-VNTR6 & 327 & $100 \%$ & Intragenic (1129799-1130125) & 50S ribosomal protein L10 & $7 \times 10^{-170}$ \\
Fnn-VNTR7 & 458 & $97 \%$ & Intragenic (1661303-1660846) & FTN_1059 hypothetical and trigger factor protein & 0 \\
\hline
\end{tabular}

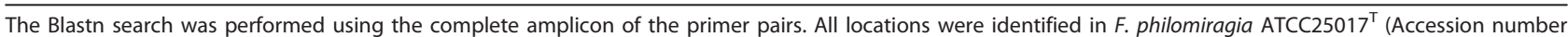
CP000937). Sequences were derived from F. philomiragia DSM $7535^{\top}$ unless otherwise stated.

VNTR-sequence obtained from $F$. noatunensis ssp. noatunensis GM2212 ${ }^{A}$.

isolate and these were termed profile I $(\mathrm{n}=8)$, profile II $(\mathrm{n}=2)$ and profile III $(\mathrm{n}=5)$; all isolates included in these profiles were collected from farmed sites with the exception of one wild isolate in profile II.

Profile I included the following isolates from farmed cod: a) four isolates collected in the period of 2004-06 from the Rogaland county, b) one isolate from Sogn and Fjordane county (2007) and c) three isolates from Møre and Romsdal county (2006-07). The two isolates in profile II were collected from Rogaland (wild cod) and Nordland (farmed cod) in 2006. A total of five isolates were included in profile III: a) three isolates, including two originating from broodfish populations, collected in Hordaland county during the period 2005-06, and b) two isolates, one sampled from farmed and one from a wild/possible escaped farmed cod in Sogn og Fjordane county in 2009. The remaining six cod isolates, including three isolates from wild cod, two from broodstock populations (usually caught as wild cod) and one from a production site, all possessed unique allele profiles. The two isolates from wild cod in Aust- and Vest Agder counties share allele profiles at five out of seven loci.

The allele profile of the Chilean isolate from Atlantic salmon, UA2660, had a unique profile sharing only one VNTR locus with the other isolates of $F$. noatinensis ssp. noatunensis.

All seven VNTRs were obtained from the isolates of $F$. noatunensis ssp. orientalis $(\mathrm{n}=4)$ with the exception of VNTR-1 from Ehime-1. None of the isolates had identical allele profiles and the allele profile of the Japanese isolate Ehime-1, from farmed Three-line grunt (Parapristipoma trilineatum), was distinct from the three Indonesian isolates from farmed tilapia (Oreochromis spp.). None of the F. philomiragia isolates $(\mathrm{n}=7)$ had identical allelic profiles.

\section{Phylogenetic relationship}

The NJ phylogenetic analysis using the seven informative VNTR loci from the 33 Francisella spp. isolates showed a subdivision of the $F$. noatunensis ssp. noatunensis isolates (Figure 2). The majority of the isolates from outbreaks of francisellosis in farmed cod group as two distinct clades. These clades were named clade I and III, as they correlate to the allele profiles (Table 5). The phylogenetic analysis also separates the Chilean UA2660 isolate from the Norwegian F. noatunensis ssp. noatunensis isolates, and differentiated among the few isolates of $F$. noatunensis ssp. orientalis, included.

\section{Stability of VNTR loci}

Examination of the stability of the VNTR loci revealed changes in repeat numbers within two VNTRs of the $F$. noatunensis ssp. noatunensis GM2212 isolate (Table 4). A shift in VNTR-1 was observed after 10 passages on Cysteine Heart Agar with Blood (CHAB) at $20^{\circ} \mathrm{C}$. This mutation consisted of the addition of one repeat, increasing the size from 7 to 8 repeats. There was also a change in VNTR-6 after passage of isolate GM2212 in cod held at $18^{\circ} \mathrm{C}$. The number of repeats was reduced from 10 to nine. The VNTRs did not change when the isolate GM2212 was passed through cod held at 10 and $14^{\circ} \mathrm{C}$. These results were verified by a repeating round of PCR and sequencing. The remaining VNTRs were not affected in this test.

\section{Linkage disequilibrium}

To avoid effects from host and geographical separation the linkages disequilibrium was calculated for $F$. noatunensis ssp. noatunensis isolates $(\mathrm{n}=22)$ only. The linkages disequilibrium was shown to be significant in the LIAN 3.5 analysis, indicating a clonal population structure for the cod isolates. Standardized $I_{\mathrm{A}} \mathrm{S}$ was calculated to 0.3925 at a significance of $\mathrm{P}_{\mathrm{para}}=3.69 \times 10^{-126}$.

\section{Epizootiological data of isolates}

There are several factors linking the isolates within the F. noatunensis clades (Figure 2, Table 5). Clade I consists of eight isolates where FnnR-001-04, -002-06, 004-06 and 017-05 were obtained from cod at one production site in Rogaland county during several outbreaks in the period of 2004-06 (Figure 1). These isolates differ from an isolate (FnnH-016-08) obtained from one of the broodfish company supplying the site. On-growth sites were not involved. Three isolates 


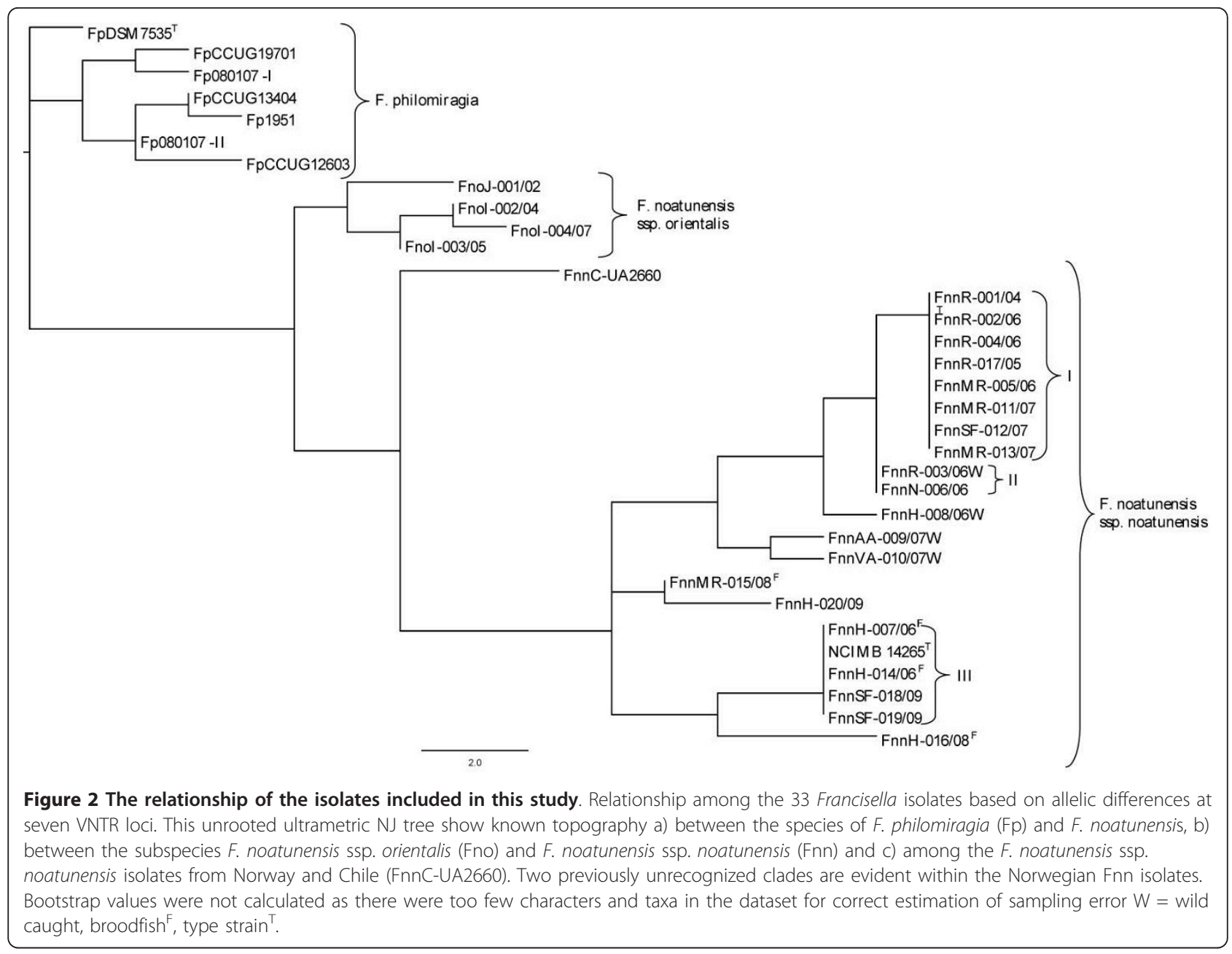

FnnMR-011-07, -013-07 and -005-06 of clade I were from another county (Møre og Romsdal), and two of these were obtained from cod with no traceable history. The third isolate FnnMR-005-06 was obtained from a site supplied by the same broodfish company as the host for isolate FnnSF-012-07, which also belongs to clade I. The latter isolate comes from another county, Sogn og Fjordane. The host for FnnMR-005-07 was kept at an on-growing site before transportation to the production site in Møre og Romsdal. Clade III consists of five isolates, three from Hordaland (FnnH-007-06, -014-06, NCIMB 14265T) and two from Sogn of Fjordane county (FnnSF018-09,-019-09) (Figure 1 and Figure 2). The latter two were sampled in the same fjord, FnnSF018-09 was isolated from farmed cod at a production site, while Fnn-019-09 was isolated from a wild caught cod. The wild caught cod had pellets in the gut and a morphology suggesting that it originated from a production site which lost fish during a francisellosis outbreak in 2009. Of the last three isolates from clade III, one (NCIMB $14265 \mathrm{~T}$ ) was isolated from cod at a production site in
Hordaland, while FnnH-007-06 and FnnH-014-06 was isolated from broodfish populations located at two sites in the same county. This broodfish company was one of the suppliers of cod to the production site in Sogn and Fjordane (FnnSF018-09) and to one production site in Hordaland (NCIMB 14265T). It is not known if the cod at the two sites, Sogn and Fjordane and Hordaland (FnnSF018-09 and NCIMB 14265T), were offspring from the broodfish populations where FnnH-007-06 and FnnH-014-06 were isolated.

\section{Discussion}

Variable Number of Tandem Repeats (VNTR) system

Whole genome sequencing of bacteria has presented new opportunities for identification of new genetic markers for separation of isolates. One such marker system can be found by looking at VNTRs, i.e., single locus sequences with short DNA repeats $[40,57]$. Micro satellites, a subset of VNTRs, with repeat motifs of nine bp or less are often targeted due to higher mutational rate $[58,59]$. However, such hyper variability, that may occur 
within some VNTRs, would complicate determination of genetic relationships among strains using this method, and hence, its use in phylogenetics may not be ideal $[45,54]$. The mechanisms behind the length variation in micro satellites is that of Slipped-Strand Mispairing (SSM) during DNA polymerase mediated DNA duplication. However, mutations involving indels of large copynumbers have been shown consistent with recombination-mediated events $[54,59,60]$. In Escherichia coli, an average mutational rate of $6.4 \times 10^{-4}$ was calculated over 28 VNTRs, and the rate seems to be dependent on intrinsic properties such as numbers of repeats [54]. Variation in copy numbers at VNTR loci of certain sizes may affect the efficiency of promoters, thus affecting the coding potential of genes dependent on the genomic locations and the indels of repeats [58,61-63]. For differentiation of bacterial isolates several VNTR loci are combined in a Multiple Locus VNTR Analysis (MLVA), a well established tool for epidemiological studies of bacteria with highly fit clonal dominance [40-42,44,58]. One such bacteria is Francisella tularensis, the agent for tularaemia [64]. This species consist of clonal geographical subspecies [39] that can be separated with the help of VNTR markers [43-46,65]. A similar approach could also be the solution for genotyping of Francisella isolates belonging to fish pathogenic Francisella spp.

Most MLVA systems applied in epidemiology are performed by multiplexing PCR-assays where VNTR size is deduced by capillary electrophoresis allowing rapid screening of large datasets [45]. Due to the relatively few VNTR-loci included and that there were only 33 isolates available for analysis in this study, sequencing was selected as a method for repeat number verification. The sequencing also detected single nucleotide polymorphisms in addition to allele size. The future potential for use of multiplex PCR assays with dyed primers and determining allele size by capillary electrophoresis is still an option and is recommended for larger datasets. This study presents a sequence based MLVA system consisting of seven VNTR loci identified in the F. noatunensis ssp. noatunensis GM2212 isolate. When applied to 33 Francisella strains including Norwegian and Asian isolates of $F$. noatunensis, the MLVA provided the best resolution shown for the fish-pathogenic Francisellae so far. Due to the preliminary genome status of the F. noatunensis ssp. noatunensis GM2212 isolate a complete VNTR locus search has not been performed, thus leaving the possibility for unidentified markers yet to be discovered. Nonetheless strain typing of F. tularensis isolates has been achieved with the use of as few as two and six VNTR markers [43,65].

The exact location of the seven VNTR markers in the F. noatunensis ssp. noatunensis is not known, however, blast searches indicate both intra- and intergenic location if the positions are homologous with that of the F. philomiragia ATCC $25017^{\mathrm{T}}$ isolate (Table 6).

The discriminatory power of the VNTR loci used in this study, was not calculated as a Simpson`s index of diversity. The reason for this is that the dataset does not fulfill the criteria of a test population proposed by van Belkum et al. (2007) [53], as isolates are predominately from outbreaks in cultured populations of cod with potential epizootic connections. The VNTR markers had a typeability of $100 \%$ among the Norwegian isolates ( $\mathrm{n}=$ 21 ), and with the exception of VNTR-1 and -3 for the UA2660 and Ehime isolate respectively, all the VNTR markers for $F$. noatunensis $(\mathrm{n}=26)$ were amplified, indicating the usability of the typing system. Stability testing showed variability within VNTR-1 and -6 from $F$. noatunensis ssp. noatunensis GM2212 isolate when grown in vitro for 10 passages at $20^{\circ} \mathrm{C}$ and in vivo in cod at $18^{\circ} \mathrm{C}$. Such single repeat changes are shown to occur in $80 \%$ of mutational events with equal chance of being an insertion or a deletion [54]. The sampled size was insufficient to assess the potential of hyper variable sites and mutation rates in the $F$. noatunensis ssp. noatunensis GM2212 isolate. VNTR mutational rates can differ across loci $[54,55]$, and could be a problem in studies of phylogenetics and epizootics. Stability and introduction of variation could be a result of bacterial phase variation and thus a result of environmental factors such as nutritional substances present in the growth medium, temperature effects $[60,63,66]$, or just simply be stochastical events. However, four isolates (FnnR-001-04, -002-06, 004-06, 017-05) from different francisellosis outbreaks at the same site during a two year period showed identical allelic profiles indicating field stability and epizootic coherence. The NJ dendrogram presented in this study should not be viewed as a phylogenetic analysis as the use of VNTRs and especially highly variable VNTRs create noise in the phylogenetic signal. The stability testing in the study shows that this may be the case of the VNTR-1 and VNTR-6. There are also too few isolates and characters (VNTRs) included in the dataset to attempt a proper analysis of genetic relationships.

\section{F. noatunensis strains}

A total of nine allele profiles were identified among the Norwegian F. noatunensis ssp. noatunensis isolates ( $\mathrm{n}=$ $21)$. Three of these contained more then one isolate (profile I $\mathrm{n}=8$, profile II $\mathrm{n}=2$ and profile III $\mathrm{n}=5$ ) and were identified using allelic profiles and visualized in the NJ dendrogram. The remaining six isolates represent unique strains of which five originated from wild cod and one from farmed cod (FnnH-020/09). Although the dataset of Norwegian isolates is small the trend is evident with only a few isolates occurring in outbreaks of francisellosis in cod culture, and a high diversity of 
strains among the isolates from wild cod. The Chilean isolate (UA2660) and the Norwegian cod isolates have previously been reported to be highly similar based on similarities in $16 \mathrm{~S}$ sequence $(99.8 \%)$ and in five housekeeping genes (Average Nucleotide Identity $=99.5 \%$ ) $[22,29]$. However, according to the VNTR analysis performed in this study, the UA2660 isolate from salmon differs at six of seven markers compared to the Norwegian $F$. noatunensis ssp. noatunensis isolates from cod, clearly separating them into two distinct branches in the NJ dendrogram. The clear separation of these isolates most likely reflects geographic origin and the ecological differences between them (host-niche, freshwater vs. marine environment). The allele profiles of the four $F$. noatunensis ssp. orientalis isolates were unique, separating them into four different genotypes. Although the sampling set is small it correctly reflects the geographical origin and, possibly, also the variation in niche. There was no clear pattern in the clustering of the F. philomiragia isolates.

Care is needed if phylogenetic relationships are to be estimated based on VNTRs [54,58], however the deeper nodes in the dendrogram (Figure 2) a) between the species of $F$. philomiragia and $F$. noatunensis, b) between the subspecies $F$. noatunensis ssp. orientalis and $F$. noatunensis ssp. noatunensis and c) among the $F$. noatunensis ssp. noatunensis isolates of Norway (NCIMB 14265T) and Chile (UA2660), were similar to the tree topology obtained based on analysis of 16S rRNA gene and datasets from housekeeping genes $[19,22]$.

\section{Epidemiology of the $F$. noatunensis}

Considering the results of the present study some reflections regarding the epizootics of the $F$. noatunensis are possible. However, it is necessary to acknowledge the shortcomings of the dataset as it covers about $40 \%$ of the official diagnosed outbreaks of francisellosis in Norway and that it only includes 4 wild isolates collected in different counties.

Generally, the low allelic diversity among the isolates collected from cultured cod compared to the isolates from wild cod, indicate that the spreading could be a result of human activity. This is also supported by the fact that the production cycle of cod in Norway involves transport of farmed cod along most of the Norwegian coast. Similarly, human activity has also been suggested as a cause for the geographical distribution of clonal isolates of Bacillus anthracis [37].

Although the VNTR markers provide a good starting point for studies of epizootics it may still be difficult to identify sources of infection as fish from different populations are mixed during the production, and, it is very difficult to avoid interactions between cultured and wild fish species. In the case of clade I with the isolates
FnnR-001-04, -002-06, 004-06 and 017-05, the new generations of cod used for restocking after initial outbreak were probably infected by the initial isolate in the population at that site. The source of the initial infection was most likely cultured cod, since isolates belonging to the same genotype have been found at production sites in other counties, while the wild type isolate (FnnR-003/ 06W) from the same county belonged to another clade.

In clade III, the isolates from a known broodfish supplier were identical to isolates from production sites where the aforementioned broodfish company was one of the suppliers of fish. Hence, all of these cases could be a result of transmission through movement of offspring from broodfish. However, the situation is complicated by the fact that the sites used for on-growth are unknown. Vertical transmission would greatly impact the disease management and needs to be addressed in further studies.

\section{Conclusions}

We present the first VNTR analysis of fish pathogenic Francisellae. Seven polymorphic microsatellites were identified in a partial genome sequence of the $F$. noatunensis ssp. noatunensis GM2212 isolate. A sequence based MLVA system of these seven VNTR-loci was applied to 33 aquatic Francisella isolates, including both $F$. philomiragia $(\mathrm{n}=7)$ and $F$. noatunensis isolates $(\mathrm{n}=$ 26). All VNTRs were amplified in the $F$. noatunensis isolates, with the exception of VNTR-1 in UA2660 and VNTR-3 in Ehime-1. Among the Norwegian F. noatunensis ssp. noatunensis isolates $(\mathrm{n}=21)$, including isolates from both farmed $(\mathrm{n}=17)$ and wild cod, a total of nine allelic profiles were identified. The majority of farmed isolates were divided into two allelic profiles, indicating low allelic variation in isolates from outbreaks in cod culture compared to isolates collected from wild cod. The allelic profile of the Chilean F. noatunensis ssp. noatunensis isolate reflected the geographical and host divergence when compared to Norwegian cod isolates. All $F$. noatunensis ssp. orientalis isolates $(\mathrm{n}=4)$ show a unique allelic profile. The four VNTRs amplified from F. philomiragia provided a unique allelic profile for all these isolates. The results show that this MLVA system should provide a good starting point for future studies of epizootics of $F$. noatunensis.

\section{Acknowledgements}

This study was financed by the Norwegian Research Council, grant number 185257.

\section{Authors' contributions}

$\varnothing J B$ was responsible for carrying out this study and was the main contributor in writing the manuscript. KFO identified the VNTR loci in the draft genome, contributed to project design and writing. AN coordinated the project, contributed to project design and reviewed all drafts of the 
manuscript All authors read, commented on and approved the final manuscript.

Received: 5 July 2010 Accepted: 24 January 2011

Published: 24 January 2011

\section{References}

1. Groff JM, Lapatra SE: Infectious Diseases Impacting the Commercial Culture of Salmonids. Journal of Applied Aquaculture 2000, 10(4):17-90.

2. Murray AG, Peeler EJ: A framework for understanding the potential for emerging diseases in aquaculture. Preventive Veterinary Medicine 2005, 67(2-3):223-235

3. Samuelsen $O B$, Nerland AH, Jorgensen $T$, Schroder MB, Swasand T, Bergh $O$ : Viral and bacterial diseases of Atlantic cod Gadus morhua, their prophylaxis and treatment: a review. Dis Aquat Organ 2006, 71(3):239-254

4. Fevolden SE, Pogson GH: Genetic divergence at the synaptophysin (Syp I) locus among Norwegian coastal and north-east Arctic populations of Atlantic cod. Journal of Fish Biology 1997, 51(5):895-908.

5. Robichaud D, Rose GA: Migratory behaviour and range in Atlantic cod: inference from a century of tagging. Fish and Fisheries 2004, 5(3):185-214

6. Otterå H: Oppdrett av torsk : næring med framtid. Norsk Fiskeoppdrett AS; 2005.

7. Knutsen H, Jorde PE, Andre C, Stenseth NC: Fine-scaled geographical population structuring in a highly mobile marine species: the Atlantic cod. Mol Ecol 2003, 12(2):385-394.

8. Salvanes AGV, Skjaeraasen JE, Nilsen T: Sub-populations of coastal cod with different behaviour and life-history strategies. Marine EcologyProgress Series 2004, 267:241-251.

9. Stransky C, Baumann H, Fevolden SE, Harbitz A, Høie H, Nedreaas KH, Salberg AB, Skarstein TH: Separation of Norwegian coastal cod and Northeast Arctic cod by outer otolith shape analysis. Fisheries Research 2008, 90(1-3):26-35.

10. Pogson $\mathrm{GH}$, Fevolden SE: Natural selection and the genetic differentiation of coastal and Arctic populations of the Atlantic cod in northern Norway: a test involving nucleotide sequence variation at the pantophysin (Pan I) locus. Mol Ecol 2003, 12(1):63-74.

11. Skarstein $\mathrm{TH}$, Westgaard Jl, Fevolden SE: Comparing microsatellite variation in north-east Atlantic cod (Gadus morhua L.) to genetic structuring as revealed by the pantophysin (Pan I) locus. Journal of Fish Biology 2007, 70(sc):271-290.

12. Jakobsen T: Coastal cod in Northern Norway. Fisheries Research Comparative biology, assessment, and management of gadoids from the North Pacific and Atlantic Oceans 1987, 5(2-3):223-234.

13. Svåsand $T$, Otterå HM, Taranger GL, Litvak $M$, Skiftesvik AB, Bjelland RM, Pavlov DA, Holm JC, Harboe T, Mangor-Jensen A, et al: The Status and Perspectives for the Species. In Culture of Cold-Water Marine Fish Edited by: E Moksness EK, Y Olsen 2007, 433-474.

14. Kjesbu AS, Taranger GL, Trippel EA: Gadoid mariculture: Development and future challenges - Introduction. Ices J Mar Sci 2006, 63(2):187-191.

15. Nylund A, Ottem KF, Watanabe K, Karlsbakk E, Krossoy B: Francisella sp (Family Francisellaceae) causing mortality in Norwegian cod (Gadus morhua) farming. Arch Microbiol 2006, 185(5):383-392.

16. Ottem KF, Nylund A, Karlsbakk E, Friis-Moller A, Krossoy B. Characterization of Francisella sp., GM2212, the first Francisella isolate from marine fish, Atlantic cod (Gadus morhua). Arch Microbiol 2007, 187(5):343-350.

17. Euzéby J: List of new names and new combinations previously effectively, but not validly, published 10.1099/ijs.0.65794-0. Int J Syst Evol Microbiol 2008, 58(1):1-2.

18. Mikalsen J, Olsen AB, Tengs T, Colquohoun DJ: Francisella philomiragia subsp noatunensis subsp nov., isolated from farmed Atlantic cod (Gadus morhua L). Int J Syst Evol Micr 2007, 57:1960-1965.

19. Ottem KF, Nylund A, Karlsbakk E, Friis-Moller A, Kamaishi T: Elevation of Francisella philomiragia subsp noatunensis Mikalsen et al. (2007) to Francisella noatunensis comb. nov [syn. Francisella piscicida Ottem et al. (2008) syn. nov.] and characterization of Francisella noatunensis subsp. orientalis subsp nov., two important fish pathogens. J Appl Microbiol 2009, 106(4):1231-1243.

20. Euzéby J: List of new names and new combinations previously effectively, but not validly, published 10.1099/ijs.0.016253-0. Int I Syst Evol Microbiol 2009, 59(7):1555-1556.
21. Euzéby J: Notification of changes in taxonomic opinion previously published outside the IJSEM 10.1099/ijs.0.016261-0. Int J Syst Evol Microbiol 2009, 59(7):1559-1560.

22. Mikalsen J, Colquhoun DJ: Francisella asiatica sp. nov. isolated from farmed tilapia (Oreochromis sp.) and elevation of Francisella philomiragia subsp. noatunensis to species rank as Francisella noatunensis comb. nov., sp. nov. Int J Syst Evol Microbiol 2009.

23. Hellberg H: Helsesituasjonen hos marin fisk 2009. In Fiskehelserapporten Edited by: Hjeltnes B 2010, 33, Veterinærinstituttet

24. Ottem KF, Nylund A, Isaksen TE, Karlsbakk E, Bergh O: Occurrence of Francisella piscicida in farmed and wild Atlantic cod, Gadus morhua L., in Norway. J Fish Dis 2008, 31(7):525-534.

25. Karlsbakk E, Omdal LM, Wangen IH, Fiksdal IU, Mortensen S, Ottem KF, Nylund A: Smittespredning ved francisellose hos torsk. In Havforskningsrapporten 2010. Edited by: Gjøsæter H, Haug T, Hauge M, Karlsen $\varnothing$, Knutsen JA, Røttingen I, Skilbrei O, Sunnset BH. Bergen: Institute of Marine Research; 2010:101-102.

26. Kamaishi $T$, Fukuda $Y$, Nishiyama M, Kawakami $H$, Matsuyama $T$, Yoshinaga T, Oseko N: Identification and pathogenicity of intracellular Francisella bacterium in three-line grunt Parapristipoma trilineatum. Fish Pathol 2005, 40(2):67-71.

27. Olsen AB, Mikalsen J, Rode M, Alfjorden A, Hoel E, Straum-Lie K, Haldorsen R, Colquhoun DJ: A novel systemic granulomatous inflammatory disease in farmed Atlantic cod, Gadus morhua L., associated with a bacterium belonging to the genus Francisella. J Fish Dis 2006, 29(5):307-311

28. Hsieh CY, Tung MC, Tu C, Chang CD, Tsai SS: Enzootics of visceral granulomas associated with Francisella-like organism infection in tilapia (Oreochromis spp.). Aquaculture 2006, 254(1-4):129-138.

29. Birkbeck TH, Bordevik M, Froystad MK, Baklien A: Identification of Francisella sp from Atlantic salmon, Salmo salar L., in Chile. J Fish Dis 2007, 30(8):505-507.

30. Ostland VE, Stannard JA, Creek JJ, Hedrick RP, Ferguson HW, Carlberg JM, Westerman ME: Aquatic Francisella-like bacterium associated with mortality of intensively cultured hybrid striped bass Morone chrysops $\mathrm{x}$ M. saxatilis. Dis Aquat Organ 2006, 72(2):135-145

31. Hsieh CY, Wu ZB, Tung MC, Tsai SS: PCR and in situ hybridization for the detection and localization of a new pathogen Francisella-like bacterium (FLB) in ornamental cichlids. Dis Aquat Organ 2007, 75(1):29-36.

32. Kamaishi T, Miwa S, Goto E, Matsuyama T, Oseko N: Mass mortality of giant abalone Haliotis gigantea caused by a Francisella sp. bacterium. Dis Aquat Organ 2010, 89(2):145-154.

33. Ottem KF, Nylund A, Karlsbakk E, Friis-Moller A, Krossoy B, Knappskog D: New species in the genus Francisella (Gammaproteobacteria; Francisellaceae); Francisella piscicida sp nov isolated from cod (Gadus morhua). Arch Microbiol 2007, 188(5):547-550.

34. Nicolas P, Mondot S, Achaz G, Bouchenot C, Bernardet JF, Duchaud E: Population structure of the fish-pathogenic bacterium Flavobacterium psychrophilum. Appl Environ Microbiol 2008, 74(12):3702-3709.

35. Frothingham R, Meeker-O'Connell WA: Genetic diversity in the Mycobacterium tuberculosis complex based on variable numbers of tandem DNA repeats. Microbiol-Uk 1998, 144:1189-1196.

36. Thibault VC, Grayon M, Boschiroli ML, Hubbans C, Overduin P, Stevenson K, Gutierrez MC, Supply P, Biet F: New variable-number tandem-repeat markers for typing Mycobacterium avium subsp paratuberculosis and $M$. avium strains: Comparison with IS900 and IS1245 restriction fragment length polymorphism typing. J Clin Microbiol 2007, 45(8):2404-2410.

37. Keim P, Price LB, Klevytska AM, Smith KL, Schupp JM, Okinaka R, Jackson PJ, Hugh-Jones ME: Multiple-locus variable-number tandem repeat analysis reveals genetic relationships within Bacillus anthracis. J Bacteriol 2000, 182(10):2928-2936

38. Klevytska AM, Price LB, Schupp JM, Worsham PL, Wong J, Keim P. Identification and characterization of variable-number tandem repeats in the Yersinia pestis genome. J Clin Microbiol 2001, 39(9):3179-3185.

39. Keim PS, Wagner DM: Humans and evolutionary and ecological forces shaped the phylogeography of recently emerged diseases. Nat Rev Microbiol 2009, 7(11):813-821

40. van Belkum A, Scherer S, van Alphen L, Verbrugh H: Short-sequence DNA repeats in prokaryotic genomes. Microbiol Mol Biol Rev 1998, 62(2):275-293.

41. van Belkum $A$ : The role of short sequence repeats in epidemiologic typing. Current Opinion in Microbiology 1999, 2(3):306-311. 
42. van Belkum A: Tracing isolates of bacterial species by multilocus variable number of tandem repeat analysis (MLVA). FEMS Immunology \& Medical Microbiology 2007, 49(1):22-27.

43. Farlow J, Smith KL, Wong J, Abrams M, Lytle M, Keim P: Francisella tularensis strain typing using multiple-locus, variable-number tandem repeat analysis. J Clin Microbiol 2001, 39(9):3186-3192.

44. Bystrom M, Bocher S, Magnusson A, Prag J, Johansson A: Tularemia in Denmark: Identification of a Francisella tularensis subsp holarctica strain by real-time PCR and high-resolution typing by multiple-locus variablenumber tandem repeat analysis. J Clin Microbiol 2005, 43(10):5355-5358.

45. Johansson A, Farlow J, Larsson P, Dukerich M, Chambers E, Bystrom M, Fox J, Chu M, Forsman M, Sjostedt A, et al: Worldwide genetic relationships among Francisella tularensis isolates determined by multiple-locus variable-number tandem repeat analysis. J Bacteriol 2004 186(17):5808-5818.

46. Vogler AJ, Birdsell D, Wagner DM, Keim P: An optimized, multiplexed multi-locus variable-number tandem repeat analysis system for genotyping Francisella tularensis. Lett Appl Microbiol 2009, 48(1):140-144.

47. Friis-Moller A, Lemming LE, Valerius NH, Bruun B: Problems in identification of Francisella philomiragia associated with fatal bacteremia in a patient with chronic granulomatous disease. J Clin Microbiol 2004, 42(4):1840-1842.

48. Berrada ZL, Goethert HK, Telford SR: Isolation of Francisella tularensis tularensis Subpopulation Ai from Missouri Lone Star Ticks. Am J Trop Med Hyg 2008, 79(6):230-230.

49. Benson G: Tandem repeats finder: a program to analyze DNA sequences. Nucleic Acids Research 1999, 27(2):573-580.

50. Ronaghi M, Karamohamed S, Pettersson B, Uhlen M, Nyren P: Real-time DNA sequencing using detection of pyrophosphate release. Anal Biochem 1996, 242(1):84-89.

51. Ronaghi $M$, Uhlen $M$, Nyren P: A sequencing method based on real-time pyrophosphate. Science 1998, 281(5375):363-+.

52. Saitou N, Nei M: The Neighbor-Joining Method - a New Method for Reconstructing Phylogenetic Trees. Mol Biol Evol 1987, 4(4):406-425.

53. van Belkum A, Tassios PT, Dijkshoorn L, Haeggman S, Cookson B, Fry NK, Fussing V, Green J, Feil E, Gerner-Smidt P, et al: Guidelines for the validation and application of typing methods for use in bacterial epidemiology. Clinical Microbiology and Infection 2007, 13:1-46.

54. Vogler AJ, Keys C, Nemoto Y, Colman RE, Jay Z, Keim P: Effect of repeat copy number on variable-number tandem repeat mutations in Escherichia coli 0157 : H7. J Bacteriol 2006, 188(12):4253-4263.

55. Vogler AJ, Keys CE, Allender C, Bailey I, Girard J, Pearson T, Smith KL, Wagner DM, Keim P: Mutations, mutation rates, and evolution at the hypervariable VNTR loci of Yersinia pestis. Mutat Res-Fundam Mol Mech Mutagen 2007, 616(1-2):145-158.

56. Haubold B, Hudson RR: LIAN 3.0: detecting linkage disequilibrium in multilocus data. Linkage Analysis. Bioinformatics 2000, 16(9):847-848

57. Nakamura Y, Leppert M, O'Connell P, Wolff R, Holm T, Culver M, Martin C,

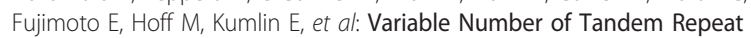
(VNTR) Markers for Human Gene Mapping. Science 1987, 235(4796):1616-1622.

58. Lindstedt BA: Multiple-locus variable number tandem repeats analysis for genetic fingerprinting of pathogenic bacteria. ELECTROPHORESIS 2005, 26(13):2567-2582.

59. Bichara M, Wagner J, Lambert IB: Mechanisms of tandem repeat instability in bacteria. Mutat Res 2006, 598(1-2):144-163.

60. Torres-Cruz J, van der Woude MW: Slipped-strand mispairing can function as a phase variation mechanism in Escherichia coli. J Bacteriol 2003, 185(23):6990-6994.

61. Renders N, Licciardello L, lisseldijk C, Sijmons M, van Alphen L, Verbrugh $H_{\text {, }}$ van Belkum A: Variable numbers of tandem repeat loci in genetically homogeneous Haemophilus influenzae strains alter during persistent colonisation of cystic fibrosis patients. FEMS Microbiol Lett 1999, 173(1):95-102.

62. Sylvestre $P$, Couture-Tosi $E$, Mock M: Polymorphism in the Collagen-Like Region of the Bacillus anthracis BclA Protein Leads to Variation in Exosporium Filament Length 10.1128/JB.185.5.1555-1563.2003. J Bacterio/ 2003, 185(5):1555-1563.

63. Moxon R, Bayliss C, Hood D: Bacterial contingency loci: the role of simple sequence DNA repeats in bacterial adaptation. Annu Rev Genet 2006, 40:307-333.
64. Francis E: The occurrence of tularemia in nature as a disease of man. Public health reports 1921, 36:1731.

65. Johansson A, Goransson I, Larsson P, Sjostedt A: Extensive allelic variation among Francisella tularensis strains in a short-sequence tandem repeat region. J Clin Microbiol 2001, 39(9):3140-3146.

66. van der Woude MW, Baumler AJ: Phase and antigenic variation in bacteria. Clin Microbiol Rev 2004, 17(3):581-+.

doi:10.1186/1746-6148-7-5

Cite this article as: Brevik et al:: Multiple-locus, variable number of tandem repeat analysis (MLVA) of the fish-pathogen Francisella noatunensis. BMC Veterinary Research 2011 7:5.

\section{Submit your next manuscript to BioMed Central and take full advantage of:}

- Convenient online submission

- Thorough peer review

- No space constraints or color figure charges

- Immediate publication on acceptance

- Inclusion in PubMed, CAS, Scopus and Google Scholar

- Research which is freely available for redistribution

Submit your manuscript at www.biomedcentral.com/submit
Ciomed Central 